\title{
Phase I and pharmacological trial of lapatinib in combination with gemcitabine in patients with advanced breast cancer
}

\author{
R. van der Noll ${ }^{1}$ - W. M. Smit ${ }^{2}$ - A. N. M. Wymenga ${ }^{2}$ - D. S. Boss ${ }^{1} \cdot$ M. Grob ${ }^{2}$ • \\ A. D. R. Huitema ${ }^{3}$ - H. Rosing ${ }^{3}$ - M. M. Tibben ${ }^{3} \cdot$ M. Keessen $^{1} \cdot$ H. Rehorst ${ }^{1}$ \\ J. H. Beijnen ${ }^{3,4}$ - J. H. M. Schellens ${ }^{1,4}$
}

Received: 29 May 2015 / Accepted: 13 August 2015 / Published online: 11 September 2015

(C) The Author(s) 2015. This article is published with open access at Springerlink.com

\begin{abstract}
Summary Background Lapatinib has proven efficacy as monotherapy and in combination with capecitabine in patients with metastatic breast cancer (MBC) overexpressing HER2 and/or EGFR. Gemcitabine also has anti-tumor activity in $\mathrm{MBC}$ and a favourable toxicity profile. In this phase I study lapatinib and gemcitabine were combined. Methods Female patients with advanced $\mathrm{BC}$ were given lapatinib once daily (QD) in 28-day cycles with gemcitabine administered on day 1, 8 and 15. Physical examinations, vital signs and blood sampling for hematology, clinical chemistry and pharmacokinetics (PK) and radiological assessments of disease were performed at regular intervals. Results In total, 33 patients were included. Six dose-limiting toxicities were observed, mostly grade 3 increases in liver function tests. Most common toxicities were fatigue (73\%), nausea (70\%), diarrhea (58\%), increases in ALAT and ASAT (55 and $52 \%$, respectively) and rash (46\%). The maximum tolerated dose was lapatinib $1250 \mathrm{mg}$ QD with gemcitabine $1000 \mathrm{mg} / \mathrm{m}^{2}$. Lapatinib and gemcitabine PK did not appear to be influenced by each other. Anti-tumor activity was observed with one patient (4\%) showing complete response and six (23\%) partial response.
\end{abstract}

J. H. M. Schellens

j.schellens@nki.nl

1 Department of Clinical Pharmacology, The Netherlands Cancer Institute, Plesmanlaan 121, 1066 CX Amsterdam, The Netherlands

2 Department of Internal Medicine, Medisch Spectrum Twente, P.O. Box 50 000, 7500 KA Enschede, The Netherlands

3 Department of Pharmacy \& Pharmacology, The Netherlands Cancer Institute, Plesmanlaan 121, 1066 CX Amsterdam, The Netherlands

4 Utrecht Institute of Pharmaceutical Sciences (UIPS), David de Wied building Universiteitsweg 99, 3584 CG Utrecht, The Netherlands
Conclusion Despite a slightly increased toxicity profile compared to their respective monotherapies, lapatinib and gemcitabine can be safely combined while showing signs of anti-tumor activity.

Keywords Lapatinib $\cdot$ Gemcitabine $\cdot$ Advanced breast cancer · Phase I trial

\section{Introduction}

Globally, breast cancer is the most frequently diagnosed cancer and the leading cause of cancer death in both economically developed and developing countries. It accounts for $23 \%$ of new cancer cases and $14 \%$ of cancer deaths worldwide (data from 2008) [1].

In the 1980s, it was discovered that overexpression of human epidermal growth factor receptor 2 (HER2/neu) is associated with poor patient prognosis and survival [2]. HER2 and its rodent analogue neu are oncogenic receptors that, when activated, can trigger multiple intracellular signalling pathways, such as the mitogen-activated protein kinase (MAPK)and phosphoinositide 3-kinase (PI3K)-pathway, leading to cell survival and proliferation [3, 4]. Therefore, this receptor rapidly became an attractive target for inhibition, leading to the development of trastuzumab (Herceptin ${ }^{\circledR}$ ) [5]. This humanized, monoclonal antibody against HER2/neu has since then become an effective treatment option for women with metastatic, HER2-overexpressing breast cancers, both as monotherapy and in combination with chemotherapy [6]. It has also shown to improve survival in the adjuvant setting in patients with HER2-overexpressing breast cancer [7].

Unfortunately, the majority of the patients treated with trastuzumab tend to develop resistance to this drug within 1 year after starting treatment. Anti-tumor 
activity may be regained by switching the combination of trastuzumab and chemotherapy into trastuzumab plus another cytotoxic agent. However, development of new therapeutic strategies is needed to overcome trastuzumab resistance [8]. Lapatinib is a dual tyrosine kinase inhibitor, targeted against both the epidermal growth factor receptor (EGFR) and HER2/neu [9]. It has shown moderate clinical anti-tumor activity as monotherapy in patients overexpressing HER2/neu and/or EGFR and has a relatively mild toxicity profile with main adverse events consisting of diarrhea and rash [10-12]. Importantly, it has shown anti-tumor activity in patients that had previously progressed on trastuzumab [13]. Adding lapatinib to a chemotherapy regimen has proven to increase its anti-tumor activity, as evidenced by the FDA and EMA approval of lapatinib in combination with capecitabine for previously treated, metastatic, HER2overexpressing breast cancer $[14,15]$.

Toxicities observed with this combination in the phase III and registration study only showed increased diarrhea and rash when compared to capecitabine alone, as was expected [16]. These encouraging results warrant further research into combining lapatinib with other cytotoxic agents.

Gemcitabine is a prodrug, which is intracellularly metabolized to its active forms difluorodeoxycytidine diphosphate and triphosphate ( $\mathrm{dFdCDP}$ and $\mathrm{dFdCTP}$ ). dFdCDP reduces the number of natural deoxynucleotides, including deoxycytidine triphosphate (dCTP). Additionally, dFdCTP competes with dCTP for incorporation into the DNA and subsequently inhibits DNA synthesis, resulting in cell death [17]. The first approval for gemcitabine was as a treatment modality for pancreatic cancer [18-20]. Due to its favourable toxicity profile, gemcitabine can be combined with other anti-cancer treatments, which for instance led to its use in patients with non-small cell lung cancer (NSCLC) and bladder cancer in combination with cisplatin $[21,22]$.

Since gemcitabine has shown activity in patients with metastatic breast cancer [23, 24], this study intended to investigate whether a combination of lapatinib and gemcitabine could be a feasible treatment option for women with advanced breast cancer. In order to explore the anti-tumor activity of this combination the optimal dose and schedule had to be determined.

\section{Patients and methods}

All patients provided written informed consent. The study was conducted in accordance with the Declaration of Helsinki, Good Clinical Practice and applicable regulatory requirements. The study was approved by the local ethical review board.

\section{Patient selection and eligibility}

This study was performed at the Netherlands Cancer Institute (NKI) in Amsterdam, the Netherlands and Medisch Spectrum Twente (MST) in Enschede, the Netherlands. It was conducted in women with advanced breast cancer who had previously been treated with an anthracycline and a taxane (either in adjuvant or palliative setting) and were then considered to be candidates for palliative chemotherapy with gemcitabine. Eligibility criteria included: age $\geq 18$ years; ECOG performance status $\leq 2$; measurable diseases according to Response Evaluation Criteria in Solid Tumors (RECIST); adequate bone marrow, hepatic and renal function (as evidenced by thrombocytes $\geq 100 * 10^{9} / \mathrm{L}$; absolute neutrophile count $\geq 1.5 * 10^{9} / \mathrm{L}$; hemoglobin $\geq 6.2 \mathrm{mmol} / \mathrm{L}$; total bilirubin $\leq 1.5 \times$ upper normal limit (ULN); serum aspartate aminotransferase (ASAT) and alanine aminotransferase $($ ALAT) $\leq 2.5 \times$ ULN and creatinine $\leq 1.5 \times \mathrm{ULN}$ ); previously treated with trastuzumab (in case of HER2-overexpression); no other investigational drugs within 30 days prior to start. Furthermore, no concomitant medication classified as a CYP3A4 inducer or inhibitor was allowed, since lapatinib is a CYP3A4 substrate. Patients with a clinically significant cardiac impairment (left ventricular ejection fraction (LVEF) of $\leq 50 \%$ ) or unstable ischemic heart disease including a myocardial infarction $(<3$ months of study entry) were not included in this study.

\section{Study design and procedures}

The primary objectives of this phase I study were to determine the safety and tolerability, maximum tolerated dose (MTD), dose-limiting toxicities (DLTs) and optimal treatment schedule of lapatinib combined with gemcitabine. Secondary objectives were to explore the pharmacokinetic (PK) profile and anti-tumor activity of the combination.

Dose escalation in this study followed a classical $3+3$ design. DLTs were defined as any of the following events determined to be possibly, probably or definitely related to treatment during the first cycle: grade $\geq 3$ non-hematological toxicities; grade $\geq 3$ nausea, vomiting or diarrhea in the presence of maximal support; grade 4 thrombocytopenia; grade 4 neutropenia for $>7$ consecutive days; or grade 3 febrile neutropenia.

The cohort below the non-tolerated dose (i.e., the cohort in which 2 or more out of 6 patients experiences a DLT) was expanded with 6 patients to confirm this dose-level as the MTD.

\section{Drug administration and dosing schedule}

One treatment cycle was defined as 28 days. Lapatinib was administered orally daily in escalating doses, starting from 
$750 \mathrm{mg}$ once daily (QD). Gemcitabine was given as a standard 30 -min intravenous infusion on day 1,8 and 15 of every cycle.

\section{Safety evaluations}

Physical examinations and the assessments of vital signs, performance status and routine clinical chemistry and hematology were performed at baseline and on day 1,8 and 15 of the first 2 treatment cycles and on day 1 and 8 of subsequent cycles. A 12-lead ECG was performed at baseline and at the start of every treatment cycle, starting at cycle 2 . A chest Xray and MUGA-scan for measurement of the LVEF was made at baseline and after every 2 treatment cycles.

Adverse events were recorded at every visit and graded according to the National Cancer Institute Common Terminology Criteria of Adverse Events (NCI-CTCAE) version 3.0 [25].

\section{Pharmacokinetic and pharmacodynamic analysis}

Plasma samples for the bioanalysis of lapatinib were collected at predose and $30 \mathrm{~min}, 1,2,4,8$ and $24 \mathrm{~h}$ after oral administration. Additional plasma samples were taken predose on day 8,15 and 29 (cycle 2 day 1). Plasma concentrations of lapatinib were measured using a validated liquid chromatography/tandem mass spectrometry method [26].

Blood samples for gemcitabine were collected prior to, at the end of infusion and 1, 2, 4, 8 and $24 \mathrm{~h}$ after start of infusion. Plasma gemcitabine $\left(2^{\prime}, 2^{\prime}\right.$ difluorodeoxycytidine, $\mathrm{dFdC}$ ) and its metabolite $2^{\prime}, 2^{\prime}-$ difluorodeoxyuridine, $\mathrm{dFdU}$ ) concentrations were analyzed as described before [27], with the exception that tetrahydrouridine was not added to the sodium-heparine blood collection tubes. Additionally, intracellular concentrations of the active metabolite of gemcitabine, difluorodeoxycytidine triphosphate ( $\mathrm{dFdCTP})$, were measured as described previously in peripheral blood mononuclear cells (PBMCs) [28] prior to, at the end of infusion and 2 and $24 \mathrm{~h}$ after start of infusion.

\section{Assessment of anti-tumor activity}

Tumor measurements were performed by CT or MRI-scan at baseline and after every 2 treatment cycles. Scans were then evaluated according to Response Evaluation Criteria in Solid Tumors (RECIST) version 1.0 [29].

Furthermore, the tumor markers cancer antigen 15.3 (CA15.3) and carcinoembryonic antigen (CEA) were measured at baseline and after every 2 treatment cycles.

\section{Results}

\section{Patient characteristics}

In total, 33 female patients with advanced breast cancer were included in this study, between November 2007 and November 2012. Table 1 shows the patient characteristics.

Four patients had to be replaced per protocol because they received $<80 \%$ of study medication during the first cycle to ensure that at least 3 subjects were evaluable for safety over the whole course of the first cycle. The median age of patients in this study was 50 years (36-73). They were heavily pretreated with approximately half of all patients (54\%) having received $\geq 4$ lines of chemotherapy. Additionally, $70 \%$ of the patients received prior hormonal therapy, $64 \%$ were previously treated with trastuzumab and $88 \%$ had received prior radiotherapy. HER2-overexpression was demonstrated in the tumors of 22 patients $(67 \%)$.

\section{Dose-Limiting Toxicities (DLTs) and Maximum Tolerated Dose (MTD)}

Five escalating dose-levels were explored in this study (see table 2). In total, six DLTs were observed across four doselevels. In five cases, the DLT concerned a grade 3 increase in

Table 1 Patient characteristics

\begin{tabular}{lll} 
Characteristic & & \\
\hline No. of patients & & 33 \\
Age, years & Median (range) & $50(36-73)$ \\
Ethnic origin, n (\%) & Caucasian & $30(91)$ \\
& East/Southeast Asian & $2(6)$ \\
& Hispanic & $1(3)$ \\
ECOG performance status, n (\%) & 0 & $11(33)$ \\
& 1 & $18(55)$ \\
No. of prior chemotherapy, n (\%) & 2 & $4(12)$ \\
& 2 & $6(18)$ \\
& 4 & $9(27)$ \\
Prior hormonal therapy, n (\%) & & $11(33)$ \\
Prior immunotherapy, $\mathrm{n}(\%)$ & & $7(21)$ \\
Prior radiotherapy, $\mathrm{n}(\%)$ & & $23(70)$ \\
HER2-overexpression, $\mathrm{n}(\%)$ & Yes & $21(64)$ \\
& No & $29(88)$ \\
LVEF, \% & Unknown & $22(67)$ \\
CA15.3, kU/L & Median (range) & $10(30)$ \\
& Median (range) & $110(11-770)$ \\
& &
\end{tabular}

Patient characteristics. $L V E F$ left ventricular ejection fraction, $C A$ cancer antigen 
Table 2 Dose-levels

\begin{tabular}{lll}
\hline Dose-level & $\begin{array}{l}\text { Lapatinib QD } \\
(\mathrm{mg})\end{array}$ & $\begin{array}{l}\text { Gemcitabine } \\
(\mathrm{mg} / \mathrm{m} 2)\end{array}$ \\
\hline 1 & 750 & 750 \\
2 & 750 & 1000 \\
3 & 1000 & 1000 \\
4 & 1250 & 1000 \\
5 & 1500 & 1000 \\
\hline
\end{tabular}

The dose-levels explored in this study

ASAT and/or ALAT. This increase generally occurred 1 to 2 weeks after start of the first cycle, leading to an interruption of lapatinib dosing and omission of gemcitabine infusions. Two patients showed progression of disease after this DLT and did not re-start treatment; in the other three patients the liver function tests recovered and cycle 2 was administered, albeit with a dose reduction of gemcitabine with $25 \%$ and lapatinib with $250 \mathrm{mg}$. Additionally, one DLT of grade $3 \mathrm{di}-$ arrhea was observed at the highest dose-level explored, despite maximal support with loperamide and ciprofloxacin. Lapatinib was interrupted and gemcitabine omitted. This patient was not re-started on treatment.

At the time the study was ongoing, only one DLT (grade 3 elevation in both ASAT and ALAT) was recorded in doselevel 3, which was then expanded. Since no other DLTs were seen in the dose expansion, the dose was escalated to doselevel 4. A second DLT (grade 3 elevation in ALAT) in doselevel 3 was not noted until study data were carefully reanalysed.

Since dose-level 5 was not considered to be tolerable with two out of six patients experiencing a DLT, the MTD was set at dose-level 4, consisting of lapatinib $1250 \mathrm{mg}$ QD (day 128) and gemcitabine $1000 \mathrm{mg} / \mathrm{m}^{2}$ (day 1,8 and 15). This doselevel was then expanded with six additional patients, none of whom experienced DLTs.

\section{Adverse events}

Treatment-related adverse events (TRAEs) observed in $\geq 10 \%$ of patients in this study are presented in Table 3.

The most commonly observed possibly, probably or definitely TRAEs were fatigue (73\%), nausea (70 \%), diarrhea (58 \%), increases in ALAT and ASAT (55 and $52 \%$, respectively), rash (46\%) and neutropenia (39\%).

Adverse events that were grade 3 or higher mostly consisted of neutropenia (39\%), elevated ALAT and ASAT (18 and $15 \%$, respectively) and diarrhea (9\%).

Interrupting lapatinib dosing and omitting gemcitabine infusion improved the observed toxicities and led to recovery of hematological and biochemical laboratory values. Nausea and diarrhea were mostly mild (grade 1-2), but in some cases these toxicities required concomitant treatment. Nausea was initially treated with metoclopramide, however, in more severe cases granisetron was required. Diarrhea sometimes required treatment with loperamide. Rash was mild (grade 2 or lower) in all cases and responded to local treatment, such as with metronidazole crème or systemic anti-histaminic treatment, such as with levocetirizine.

While there were five patients who demonstrated a median decrease in LVEF of $10 \%$ (range 8-14\%) after two cycles, the patients who remained on study for six cycles or longer showed stable LVEF values.

\section{Pharmacokinetics}

PK parameters and plasma concentration-time curves of lapatinib and gemcitabine ( $\mathrm{dFdC}$ and $\mathrm{dFdU})$ and intracellular concentrations of dFdCTP are presented in table 4 and Fig. 1.

\section{Lapatinib}

Plasma samples for the PK of lapatinib were collected and analyzed in 28 patients. The PK of lapatinib showed high interpatient variability (see Fig. 1a). The median time to maximum concentration $\left(\mathrm{T}_{\max }\right)$ was mostly observed at $4.0 \mathrm{~h}$ (range 2.0-8.1). The maximum plasma concentration $\left(\mathrm{C}_{\max }\right)$ increased with dose and this increase appeared to be doseproportional. Since the blood sampling did not cover $>80 \%$ of the area under the plasma concentration-time curve (AUC) due to a long elimination phase, the $\mathrm{AUC}_{0-\infty}$ and terminal halflife $\left(t_{1 / 2}\right)$ could not be determined from the obtained data.

\section{Gemcitabine}

The PK parameters for $\mathrm{dFdC}$ and $\mathrm{dFdU}$ were determined in plasma collected from 30 patients. See Fig. $1 b$ and c.

The dose-normalized $\mathrm{C}_{\max }$ and $\mathrm{AUC}_{0-24}$ did not differ significantly amongst dose-levels, although there was high variation in the first three patients on study.

For the metabolite $\mathrm{dFdU}$, the $\mathrm{C}_{\max }$ followed closely after $\mathrm{dFdC}$, indicating rapid formation of this metabolite. Both $\mathrm{C}_{\max }$ and $\mathrm{AUC}_{0-\infty}$ increased dose-proportionally across the different dose-levels.

\section{Pharmacodynamics}

PBMCs of 26 patients were available for the analysis of intracellular dFdCTP concentration. However, in about half of the patients the $\mathrm{dFdCTP}$ measurements were below the lower limit of quantification (LLOQ) and were therefore not used in further analyses. The results obtained in 13 patients are shown in Fig. 1d. High variability was observed; therefore $\mathrm{AUC}_{0-\infty}$ and $\mathrm{t}_{1 / 2}$ could not be determined. 
Table 3 Treatment-related adverse events

\begin{tabular}{|c|c|c|c|c|c|c|c|}
\hline \multirow[t]{2}{*}{ Adverse event } & \multirow{2}{*}{ No. of patients } & \multicolumn{5}{|c|}{ Dose-level } & \multirow{2}{*}{$\begin{array}{l}\text { Total } \\
33\end{array}$} \\
\hline & & 1 & $\begin{array}{l}2 \\
4\end{array}$ & 3 & $\begin{array}{l}7 \\
10\end{array}$ & $\begin{array}{l}5 \\
8\end{array}$ & \\
\hline \multirow[t]{2}{*}{ Fatigue } & All grades & $2(67)$ & $3(75)$ & $7(88)$ & $7(70)$ & $5(63)$ & $24(73)$ \\
\hline & Grade $\geq 3$ & 0 & 0 & $1(13)$ & 0 & 0 & $1(3)$ \\
\hline \multirow[t]{2}{*}{ Nausea } & All grades & $1(33)$ & $4(100)$ & $7(88)$ & $4(40)$ & $7(88)$ & $23(70)$ \\
\hline & Grade $\geq 3$ & 0 & 0 & $1(13)$ & 0 & 0 & $1(3)$ \\
\hline \multirow[t]{2}{*}{ Diarrhea } & All grades & $2(67)$ & $2(50)$ & $4(50)$ & $5(50)$ & $6(75)$ & $19(58)$ \\
\hline & Grade $\geq 3$ & 0 & 0 & $1(13)$ & $1(10)$ & $1(13)$ & $3(9)$ \\
\hline \multirow[t]{2}{*}{ Elevated ALAT } & All grades & $1(33)$ & $3(75)$ & $5(63)$ & $5(50)$ & $4(50)$ & $18(55)$ \\
\hline & Grade $\geq 3$ & 0 & $1(25)$ & $2(25)$ & $1(10)$ & $2(25)$ & $6(18)$ \\
\hline \multirow[t]{2}{*}{ Elevated ASAT } & All grades & $1(33)$ & $3(75)$ & $5(63)$ & $4(40)$ & $4(50)$ & $17(52)$ \\
\hline & Grade $\geq 3$ & 0 & $1(25)$ & $3(38)$ & & $1(13)$ & $5(15)$ \\
\hline \multirow[t]{2}{*}{ Rash* } & All grades & 0 & $2(50)$ & $4(50)$ & $5(50)$ & $4(50)$ & $15(46)$ \\
\hline & Grade $\geq 3$ & 0 & 0 & 0 & 0 & 0 & 0 \\
\hline \multirow[t]{2}{*}{ Neutropenia } & All grades & $2(67)$ & $2(50)$ & $1(13)$ & $5(50)$ & $3(38)$ & $13(39)$ \\
\hline & Grade $\geq 3$ & $2(67)$ & $2(50)$ & $1(13)$ & $5(50)$ & $3(38)$ & $13(39)$ \\
\hline \multirow[t]{2}{*}{ Vomiting } & All grades & 0 & $2(50)$ & $5(63)$ & $2(20)$ & $2(25)$ & $11(33)$ \\
\hline & Grade $\geq 3$ & 0 & 0 & $1(13)$ & 0 & 0 & $1(3)$ \\
\hline \multirow[t]{2}{*}{ Fever } & All grades & $1(33)$ & $1(25)$ & $2(25)$ & $2(20)$ & $2(25)$ & $8(24)$ \\
\hline & Grade $\geq 3$ & 0 & 0 & 0 & 0 & 0 & 0 \\
\hline \multirow[t]{2}{*}{ Mucositis\# } & All grades & 0 & $1(25)$ & $1(13)$ & $2(20)$ & $3(38)$ & $7(21)$ \\
\hline & Grade $\geq 3$ & 0 & 0 & 0 & 0 & 0 & 0 \\
\hline
\end{tabular}

Treatment-related adverse events per dose-level. *includes desquamation, acneiform, erythema. \# both clinical examination and symptomatic

\section{Anti-tumor activity}

Out of the 33 patients included in this study, 26 had at least one response evaluation (see table 5); seven patients had gone off study without receiving one full cycle because of rapid clinical disease progression. One patient (4\%) demonstrated radiological complete response (CR) and another six patients (23\%) achieved a partial response (PR), resulting in an overall response rate (ORR: $\mathrm{CR}+\mathrm{PR}$ ) of $27 \%$. Five of the patients that had radiological PR also demonstrated clear reductions in their tumor markers (both CA15.3 and CEA). An additional 12 patients (46\%) had stable disease (SD) as best response. Radiological responses were mostly observed at higher doselevels ( $\geq$ level 3). Furthermore, the patient with $C R$ and 5/6 patients with PR demonstrated tumors that overexpressed HER2.

Median duration on study for the evaluable population was 13 weeks, ranging from 2 to 49 weeks.

\section{Discussion}

In this phase I study, the combination of lapatinib with gemcitabine did not result in unexpected toxicities. The
MTD of the combination was defined at lapatinib $1250 \mathrm{mg}$ QD (day 1-28) with gemcitabine $1000 \mathrm{mg} / \mathrm{m}^{2}$ (day 1, 8 and 15). The most frequently observed TRAEs were in line with toxicities that are observed with gemcitabine and lapatinib monotherapy. Both frequency and severity of TRAEs increased with escalating dose-levels. The DLTs that were observed in this study did not correspond to higher exposures to study drug, except for the patient who experienced grade 3 diarrhea despite maximal support with loperamide and ciprofloxacin. This patient showed the highest exposure to lapatinib out of all patients on study, which could explain the persisting toxicity. The most common adverse events seen with lapatinib, diarrhea and rash (42 and $31 \%$, respectively, in the lapatinib monotherapy phase I study) [10], were also observed in this study albeit with slightly increased frequency (58 and $46 \%$, respectively). In all cases, rash was mild (grade 1-2) and appeared to respond to local or systemic treatment. The diarrhea was also mostly mild and manageable with concomitant treatment of loperamide.

Hematological and biochemical toxicities, such as neutropenia and elevated ALAT and ASAT, were also increased in the lapatinib/gemcitabine combination $(39,55$ and $52 \%$, respectively) when compared to gemcitabine monotherapy (26, 39 and $31 \%$, respectively) [18]. 
Table 4 Pharmacokinetic parameters

\begin{tabular}{|c|c|c|c|c|c|}
\hline Dose-level & 1 & 2 & 3 & 4 & 5 \\
\hline Lapatinib QD (mg) & 750 & 750 & 1000 & 1250 & 1500 \\
\hline Gemcitabine (mg/m2) & 750 & 1000 & 1000 & 1000 & 1000 \\
\hline \multicolumn{6}{|l|}{ Lapatinib (median (range)) } \\
\hline & $n=3$ & $n=4$ & $n=7$ & $n=9$ & $n=7$ \\
\hline $\mathrm{Cmax}(\mathrm{ng} / \mathrm{mL})$ & $807(436-1614)$ & $872(540-1200)$ & $818(450-1294)$ & $1258(573-2231)$ & $1314(1030-3108)$ \\
\hline Dose-normalized Cmax (ng/mL*mg) & $1.1(0.6-2.2)$ & $1.2(0.7-1.6)$ & $0.8(0.5-1.3)$ & $1.0(0.5-1.8)$ & $0.9(0.7-2.1)$ \\
\hline Tmax (hr) & $4.0(4.0-4.1)$ & $4.0(2.1-4.4)$ & $4.0(2.0-8.1)$ & $4.0(2.1-8.0)$ & $4.2(4.0-6.9)$ \\
\hline \multicolumn{6}{|l|}{ Gemcitabine (median (range)) } \\
\hline $\mathrm{dFdC}$ & $n=3$ & $n=4$ & $n=7$ & $n=9$ & $n=7$ \\
\hline Cmax (ug/mL) & $9.5(1.2-4.6)$ & $9.1(7.4-13.0)$ & $10.9(4.4-14.8)$ & $9.2(5.0-21.5)$ & $10.2(1.4-20.0)$ \\
\hline Dose-normalized Cmax (ng/mL*mg) & $7.6(1.0-38.4)$ & $5.4(4.7-6.2)$ & $6.2(2.3-7.4)$ & $4.8(0.6-12.1)$ & $5.7(0.9-10.5)$ \\
\hline AUC0-24 (ug*hr/mL) & $7.1(1.0-24.8)$ & $6.4(5.2-7.6)$ & $7.9(3.3-11.3)$ & $7.8(0.6-17.1)$ & $6.8(1.2-10.5)$ \\
\hline $\mathrm{dFdU}$ & $n=3$ & $n=4$ & $n=7$ & $n=9$ & $n=7$ \\
\hline Cmax (ug/mL) & $20.8(18.2-44.3)$ & $46.4(29.5-59.3)$ & $33.5(26.4-52.4)$ & $36.4(33.3-63.9)$ & $37.6(26.8-54.9)$ \\
\hline Dose-normalized Cmax (ng/mL*mg) & $16.6(14.3-36.9)$ & $24.1(18.4-37.8)$ & $19.9(16.5-26.2)$ & $21.4(17.9-39.9)$ & $21.4(15.8-28.9)$ \\
\hline 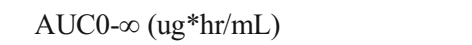 & $196(185-202)$ & $282(232-505)$ & $272(188-496)$ & $306(226-461)$ & $324(272-359)$ \\
\hline Terminal half-life (t1/2) (hr) & $9.1(8.1-11.5)$ & $9.0(7.5-9.9)$ & $10.3(6.3-11.0)$ & $8.9(8.0-9.7)$ & $9.6(8.1-13.4)$ \\
\hline dFdCTP & $n=3$ & $n=3$ & $n=5$ & $n=2$ & NA \\
\hline Cmax (pmol/10*6 cells) & $63(51-69)$ & $59(54-62)$ & $42(33-84)$ & $147(128-165)$ & NA \\
\hline Tmax (hr) & $2.0(0.6-2.0)$ & $0.8(0.6-2.0)$ & $1.9(0.7-2.1)$ & $2.0(2.0-2.1)$ & NA \\
\hline
\end{tabular}

Pharmacokinetic parameters of lapatinib and gemcitabine (dFdC, $\mathrm{dFdU}$ and $\mathrm{dFdCTP}$ ) per dose-level

Overall, these data suggest that combining these compounds does result in slightly increased toxicity when compared to either of these agents alone. This resulted in a lower lapatinib dose in the MTD of this study $(1250 \mathrm{mg})$ than the dose that is recommended as monotherapy $(1500 \mathrm{mg})$. Gemcitabine however could be administered at the recommended monotherapy dose of $1000 \mathrm{mg} / \mathrm{m}^{2}$.

The PK of lapatinib showed high interpatient variability. The dose-normalized $\mathrm{C}_{\max }$ did not differ significantly between the different dose-levels. However, no sampling was done for lapatinib alone thus no direct treatment comparisons could be made. Furthermore, patient numbers were small, making it difficult to draw definitive conclusions about the influence of gemcitabine on lapatinib PK.

Less variation was seen in the PK of gemcitabine $(\mathrm{dFdC})$ and its metabolite dFdU. For both $\mathrm{dFdC}$ and $\mathrm{dFdU}, \mathrm{PK}$ appeared to be similar to gemcitabine monotherapy [30], suggesting that co-administration of lapatinib did not influence gemcitabine PK.

The measurement of dFdCTP was performed in about half of the patients, since many of the samples were below the LLOQ. We suspect that this might be due to the sample processing. Most of the later samples were not washed with icecold PBS as described in the validated method [28] or processed on ice, which could have led to an increase in the rate of degradation of dFdCTP. In the subjects where dFdCTP could be determined it showed very high variability, although $\mathrm{C}_{\max }$ values found were similar to those in literature with similar doses of gemcitabine [31].

Although not the primary objective of this study, the ORR observed in this study ( $27 \%$ for all evaluable patients; $21 \%$ for evaluable patients whose tumor overexpressed HER2) is in line with the lapatinib/capecitabine (1250 mg continuously/ $2000 \mathrm{mg} / \mathrm{m}^{2}$ on day $1-14$ ) combination (ORR of $22 \%$ ) in the phase III trial in a similar population.(16) However, this conclusion has to be considered carefully since patient numbers were much smaller in this phase I study (26 patients evaluable for response compared to 163 patients in the Geyer study) and in this study HER2-expression was not an inclusion criterium.

The combination of lapatinib with gemcitabine (and oxaliplatin) has been investigated clinically before in patients with pancreatic and biliary cancer. In a phase I study in this population the MTD of lapatinib with gemcitabine was set at $1500 \mathrm{mg}$ and $1000 \mathrm{mg} / \mathrm{m}^{2}$ respectively, with only 1 DLT of grade 3 diarrhea [32]. A subsequent phase II study of lapatinib/gemcitabine was performed in patients with metastatic pancreatic cancer. Toxicities were mostly hematologic (30\% experienced grade 3 or 4 neutro- or thrombocytopenia); fatigue, diarrhea, elevated ASAT/ALAT and anorexia were the most frequent non-hematological grade $\geq 2$ adverse events. Unfortunately, the combination failed to improve the overall 
Fig. 1 Plasma concentrationtime curves of lapatinib (a), dFdC (b), dFdU (c) and a boxplot showing the median and range of $\mathrm{dFdCTP}$ over time $(\mathbf{d})$
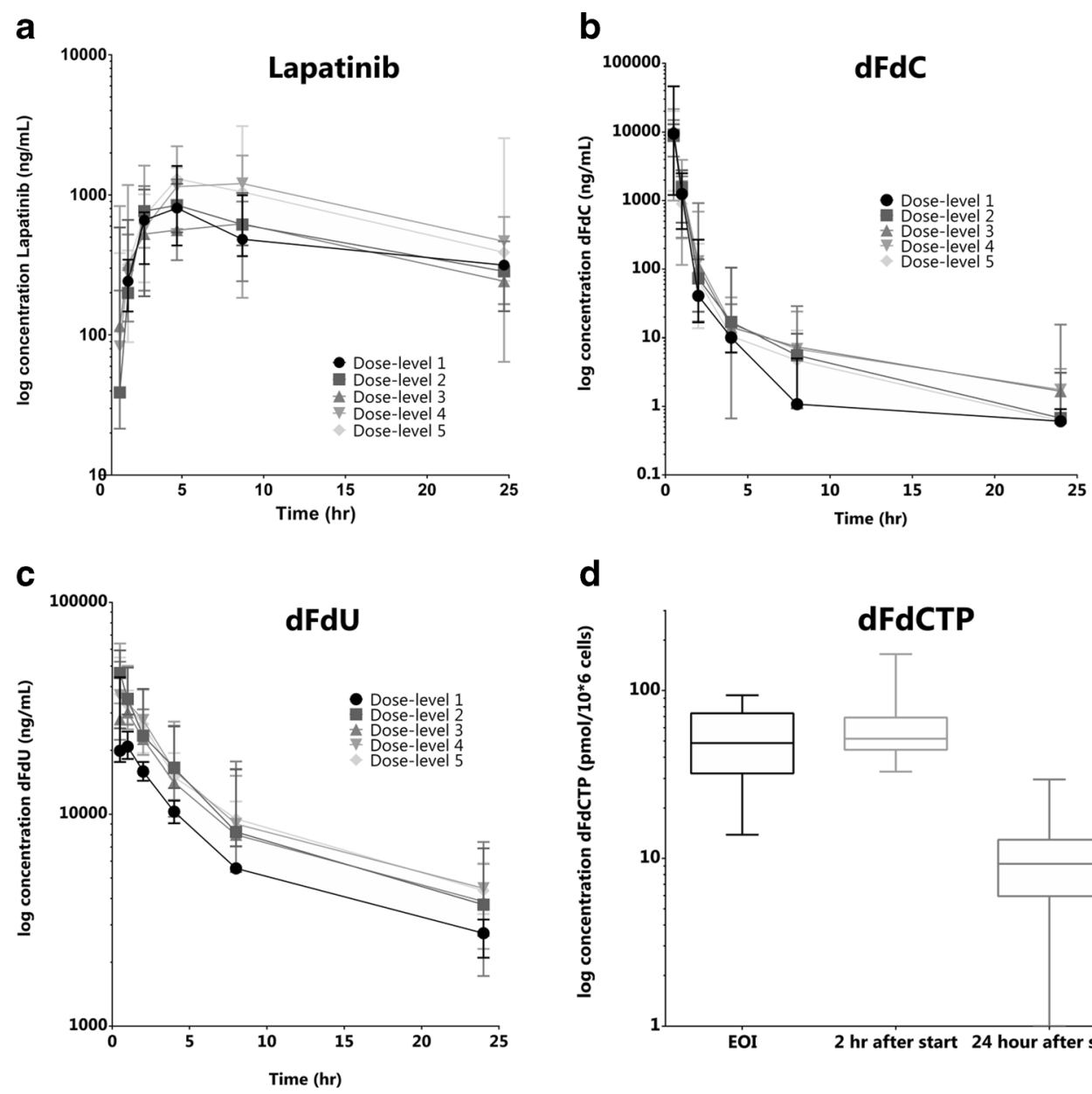

survival rate in this patient population [33]. In a recent preclinical study lapatinib was tested in combination with gemcitabine to investigate whether these drugs showed synergistic or antagonistic effects in pancreatic cancer cell lines. There was no clear effect observed and thus the authors concluded that lapatinib may not enhance the anti-tumor effects of gemcitabine in pancreatic cancer [34]. In contrast and consistent with our study, encouraging evidence of lapatinib in combination with gemcitabine was demonstrated in a case report of a female with metastatic, HER2-overexpressing breast cancer who developed a complete clinical response for 1 year after being treated with this combination (lapatinib $1250 \mathrm{mg}$, later reduced to $1000 \mathrm{mg}$ and gemcitabine 1000 $\left.\mathrm{mg} / \mathrm{m}^{2}\right)$ [35].

Table 5 Anti-tumor activity

\begin{tabular}{|c|c|c|c|c|c|c|c|}
\hline \multirow[t]{2}{*}{ Dose-level } & \multirow[t]{2}{*}{ No. of patients } & \multirow[t]{2}{*}{ Median treatment duration (weeks), range } & \multicolumn{3}{|c|}{ Response by RECIST, n (\%) } & \multirow[b]{2}{*}{$P D$} & \multirow[b]{2}{*}{$N E$} \\
\hline & & & $C R$ & $P R$ & $S D$ & & \\
\hline 1 & 3 & $14(2-30)$ & 0 & 0 & $1(33)$ & $2(67)$ & 0 \\
\hline 2 & 4 & $8.5(7-14)$ & 0 & 0 & $4(100)$ & 0 & 0 \\
\hline 3 & 8 & $14(0-32)$ & $1(12)$ & $1(12)$ & $2(25)$ & $2(25)$ & $1(12)$ \\
\hline 4 & 10 & $6(0-39)$ & 0 & $3(30)$ & $3(30)$ & $2(20)$ & $1(10)$ \\
\hline 5 & 8 & $10.5(1-49)$ & 0 & $2(25)$ & $2(25)$ & $1(12)$ & $1(12)$ \\
\hline Total & 33 & $8(0-49)$ & $1(3)$ & $6(18)$ & $12(36)$ & $7(21)$ & $3(9)$ \\
\hline
\end{tabular}

Best tumor response by RECIST observed during this study per dose-level. $C R$ complete response, $P R$ partial response, $S D$ stable disease, $P D$ progressive disease, $N E$ not evaluable. 
Overall, despite a slight increase in toxicity profile compared to their monotherapies, the combination of lapatinib with gemcitabine appears to be a safe treatment regimen for patients with advanced breast cancer, while showing preliminary signs of anti-tumor activity. Combining these two compounds did not appear to influence each other's PK profile. Although further studies are needed to confirm that the antitumor activity is comparable to the lapatinib/capecitabine combination, the lapatinib combination with gemcitabine could be a new treatment modality for these patients after progressing on treatment with an anthracycline and trastuzumab.

Acknowledgments The contribution of H.H. Helgason, MD currently HAGA hospital, The Hague, The Netherlands to the protocol writing is gratefully acknowledged.

The contribution of Y. Groot, B. Dufourny and P. Hagen, Department of Clinical Pharmacology, The Netherlands Cancer Institute, Amsterdam, The Netherlands to the data monitoring and managing is gratefully acknowledged.

We are grateful to dr. R. van Dorp, GSK Zeist, The Netherlands for general support.

Conflict of interest The authors declare that they have no conflict of interest.

Open Access This article is distributed under the terms of the Creative Commons Attribution 4.0 International License (http:// creativecommons.org/licenses/by/4.0/), which permits unrestricted use, distribution, and reproduction in any medium, provided you give appropriate credit to the original author(s) and the source, provide a link to the Creative Commons license, and indicate if changes were made.

\section{References}

1. Jemal A, Bray F, Center MM, Ferlay J, Ward E, Forman D (2011) Global cancer statistics. CA Cancer J Clin 61:69-90

2. Slamon DJ, Clark GM, Wong SG, Levin WJ, Ullrich A, McGuire WL (1987) Human breast cancer: correlation of relapse and survival with amplification of the HER-2/neu oncogene. Science 235: 177-182

3. Yarden Y, Sliwkowski MX (2001) Untangling the ErbB signalling network. Nat Rev Mol Cell Biol 2:127-137

4. Moasser MM (2007) The oncogene HER2: its signaling and transforming functions and its role in human cancer pathogenesis. Oncogene 26:6469-6487

5. Goldenberg MM (1999) Trastuzumab, a recombinant DNA-derived humanized monoclonal antibody, a novel agent for the treatment of metastatic breast cancer. Clin Ther 21:309-318

6. Hudis CA (2007) Trastuzumab-mechanism of action and use in clinical practice. N Engl J Med 357:39-51

7. Slamon D, Eiermann W, Robert N, Pienkowski T, Martin M, Press $M$ et al (2011) Adjuvant trastuzumab in HER2-positive breast cancer. N Engl J Med 365:1273-1283

8. Nahta R, Esteva FJ (2006) HER2 therapy: molecular mechanisms of trastuzumab resistance. Breast Cancer Res 8:215

9. Johnston SRD, Leary A (2006) Lapatinib: a novel EGFR/HER2 tyrosine kinase inhibitor for cancer. Drugs Today 42:441-453

10. Burris HA, Hurwitz HI, Dees EC, Dowlati A, Blackwell KL, O’Neil B et al (2005) Phase I safety, pharmacokinetics, and clinical activity study of lapatinib (GW572016), a reversible dual inhibitor of epidermal growth factor receptor tyrosine kinases, in heavily pretreated patients with metastatic carcinomas. J Clin Oncol 23: $5305-5313$

11. Burstein HJ, Storniolo AM, Franco S, Forster J, Stein S, Rubin S et al (2008) A phase II study of lapatinib monotherapy in chemotherapy-refractory HER2-positive and HER2-negative advanced or metastatic breast cancer. Ann Oncol 19:1068-1074

12. Kaufman B, Trudeau M, Awada A, Blackwell K, Bachelot T, Salazar V et al (2009) Lapatinib monotherapy in patients with HER2-overexpressing relapsed or refractory inflammatory breast cancer: final results and survival of the expanded HER2+ cohort in EGF103009, a phase II study. Lancet Oncol 10:581-588

13. Blackwell KL, Pegram MD, Tan-Chiu E, Schwartzberg LS, Arbushites MC, Maltzman JD et al (2009) Single-agent lapatinib for HER2-overexpressing advanced or metastatic breast cancer that progressed on first- or second-line trastuzumab-containing regimens. Ann Oncol 20:1026-1031

14. Ryan Q, Ibrahim A, Cohen MH, Johnson J, Ko C, Sridhara R et al (2008) FDA drug approval summary: lapatinib in combination with capecitabine for previously treated metastatic breast cancer that overexpresses HER-2. Oncologist 13:1114-1119

15. European Medicines Agency. Tyverb lapatinib. 2013 (2008) http:// www.ema.europa.eu/ema/index.jsp?curl=pages/medicines/human/ medicines/000795/human_med_001120.jsp\&mid= WC0b01ac058001d124. Accessed 1 April 2014

16. Geyer CE, Forster J, Lindquist D, Chan S, Romieu CG, Pienkowski $T$ et al (2006) Lapatinib plus capecitabine for HER2-positive advanced breast cancer. N Engl J Med 355:2733-2743

17. Plunkett W, Huang P, Xu YZ, Heinemann V, Grunewald R, Gandhi V (1995) Gemcitabine: metabolism, mechanisms of action, and self-potentiation. Semin Oncol 22:3-10

18. Burris HA, Moore MJ, Andersen J, Green MR, Rothenberg ML, Modiano MR et al (1997) Improvements in survival and clinical benefit with gemcitabine as first-line therapy for patients with advanced pancreas cancer: a randomized trial. J Clin Oncol 15:24032413

19. Food and Drug Administration. Gemzar (2006) http://www.cancer. gov/aboutcancer/treatment/drugs/fda-gemcitabine-hydrochloride. Accessed 1 April 2014

20. European Medicines Agency. Gemzar (2008) http://www.ema. europa.eu/ema/index.jsp?curl=pages/medicines/human/referrals/ Gemzar/human_referral_000031.jsp. Accessed 1 April 2014

21. Cardenal F, López-Cabrerizo MP, Antón A, Alberola V, Massuti B, Carrato A et al (1999) Randomized phase III study of gemcitabinecisplatin versus etoposide-cisplatin in the treatment of locally advanced or metastatic non-small-cell lung cancer. J Clin Oncol 17: $12-18$

22. Von der Maase H, Sengelov L, Roberts JT, Ricci S, Dogliotti L, Oliver T et al (2005) Long-term survival results of a randomized trial comparing gemcitabine plus cisplatin, with methotrexate, vinblastine, doxorubicin, plus cisplatin in patients with bladder cancer. J Clin Oncol 23:4602-4608

23. Brodowicz T, Kostler WJ, Möslinger R, Tomek S, Vaclavik I, Herscovici V et al (2000) Single-agent gemcitabine as secondand third-line treatment in metastatic breast cancer. Breast 9:338342

24. Blackstein M, Vogel CL, Ambinder R, Cowan J, Iglesias J, Melemed A (2002) Gemcitabine as first-line therapy in patients with metastatic breast cancer: a phase II trial. Oncology 62:2-8

25. Trotti A, Colevas AD, Setser A, Rusch V, Jaques D, Budach V et al (2003) CTCAE v3.0: development of a comprehensive grading system for the adverse effects of cancer treatment. Semin Radiat Oncol 13:176-181

26. Lankheet NAG, Hillebrand MJX, Rosing H, Schellens JHM, Beijnen JH, Huitema ADR (2013) Method development and 
validation for the quantification of dasatinib, erlotinib, gefitinib, imatinib, lapatinib, nilotinib, sorafenib and sunitinib in human plasma by liquid chromatography coupled with tandem mass spectrometry. Biomed Chromatogr 27:466-476

27. Veltkamp SA, Jansen RS, Callies S, Pluim D, Visseren-Grul CM, Rosing $\mathrm{H}$ et al (2008) Oral administration of gemcitabine in patients with refractory tumors: a clinical and pharmacologic study. Clin Cancer Res 14:3477-3486

28. Veltkamp SA, Hillebrand MJX, Rosing H, Jansen RS, Wickremsinhe ER, Perkins EJ et al (2006) Quantitative analysis of gemcitabine triphosphate in human peripheral blood mononuclear cells using weak anion-exchange liquid chromatography coupled with tandem mass spectrometry. J Mass Spectrom 41: $1633-1642$

29. Therasse P, Arbuck SG, Eisenhauer EA, Wanders J, Kaplan RS, Rubinstein L et al (2000) New guidelines to evaluate the response to treatment in solid tumors. European Organization for Research and Treatment of Cancer, National Cancer Institute of the United States, National Cancer Institute of Canada. J Natl Cancer Inst 92: 205-216
30. Abbruzzese JL, Grunewald R, Weeks EA, Gravel D, Adams T, Nowak B et al (1991) A phase I clinical, plasma, and cellular pharmacology study of gemcitabine. J Clin Oncol 9:491-498

31. Kroep JR, Giaccone G, Voorn DA, Smit EF, Beijnen JH, Rosing H et al (1999) Gemcitabine and paclitaxel: pharmacokinetic and pharmacodynamic interactions in patients with non-small-cell lung cancer. J Clin Oncol 17:2190-2197

32. Safran H, Miner T, Resnick M, Dipetrillo T, McNulty B, Evans D et al (2008) Lapatinib/gemcitabine and lapatinib/gemcitabine/ oxaliplatin: a phase I study for advanced pancreaticobiliary cancer. Am J Clin Oncol 31:140-144

33. Safran H, Miner T, Bahary N, Whiting S, Lopez CD, Sun W et al (2011) Lapatinib and gemcitabine for metastatic pancreatic cancer. Am J Clin Oncol 34:50-52

34. Murata A, Nakata B, Komoto M, Hirata K, Kimura K, Amano R et al (2013) In vitro effects of lapatinib with gemcitabine for pancreatic cancer cells. Hepatogastroenterology 60:1484-1487

35. Gasent Blesa JM, Laforga Canales J, Candel VA (2010) One year of complete clinical response in a metastatic breast cancer patient treated with a combination of lapatinib and gemcitabine. Curr Oncol 17:64-68 